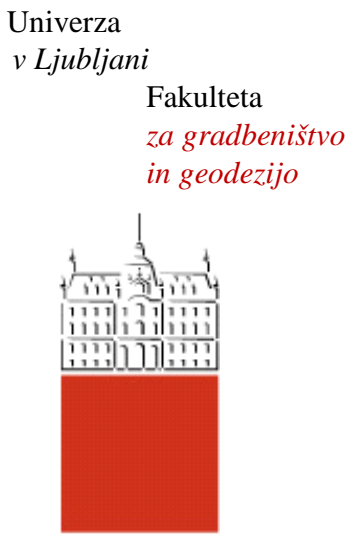

Jamova cesta 2

1000 Ljubljana, Slovenija

http://www3.fgg.uni-lj.si/

\section{DRUGG - Digitalni repozitorij UL FGG http://drugg.fgg.uni-lj.si/}

Ta članek je avtorjeva zadnja recenzirana različica, kot je bila sprejeta po opravljeni recenziji.

Prosimo, da se pri navajanju sklicujte na bibliografske podatke, kot je navedeno:
University
of Ljubljana

Faculty of

Civil and Geodetic

Engineering

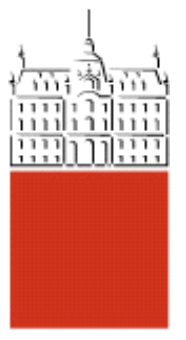

Jamova cesta 2

SI - 1000 Ljubljana, Slovenia

http://www3.fgg.uni-lj.si/en/

DRUGG - The Digital Repository http://drugg.fgg.uni-lj.si/

This version of the article is author's manuscript as accepted for publishing after the review process.

When citing, please refer to the publisher's bibliographic information as follows:

Trtnik G., Turk G. 2013. Influence of superplasticizes on the evolution of ultrasonic P-wave velocity through cement pastes at early age. Cement and concrete research 51:22-31. doi: 10.1016/j.cemconres.2013.04.007. 


\title{
Influence of superplasticizers on the evolution of ultrasonic P-wave velocity through cement pastes at early age
}

\author{
G. Trtnik ${ }^{a^{*}}$, G. Turk ${ }^{b}$ \\ ${ }^{a}$ IGMAT Building Materials Institute, Polje 351c, 1000 Ljubljana, Slovenia. \\ ${ }^{\mathrm{b}}$ University of Ljubljana, Faculty of Civil and Geodetic Engineering, Jamova 2, 1000 Ljubljana
}

\begin{abstract}
The paper discusses a possibility of using an ultrasonic wave transmission method to study the influence of superplasticizers on the formation of structure of cement pastes at early ages. When compared to mixtures without additives, lower P-wave velocity was found through superplasticized cement pastes, indicating that superplasticizers prevent formation of a solid network frame. Comparing to sulfonate naphthalene-formaldehyde superplasticizers, polycarboxylate ether (PCE) admixtures retarded the solid network frame development more intensively, resulting in a plateau on a P-wave velocity curve during the setting period. The length of the plateau is proportional to the dosage of the PCE and inversely proportional to the specific surface area of the hydration products developed, proving that the specific surface area of a solid phase affects the performance of the PCEs. Validation of ultrasonic results was determined on the basis of the temperature evolution of the material in time.
\end{abstract}

Keywords: Hydration (A), Microstructure (B), Cement Paste (D), Superplasticizers, Ultrasound.

\section{Introduction}

Admixtures have been used in concrete production for at least two millennia, but their application has accelerated greatly in the last decades. Among others, different types of superplasticizers (SPs) are used extensively mainly to modify some properties of cement based materials in the fresh state or more specifically, to yield high workability at low water/cement ratios. However, despite their widespread utilization, these polymers are currently still the subject of many studies because new classes of SPs are being produced constantly.

In general, SPs work as dispersants mainly after their adsorption on the surfaces of the solid phases developed during the hydration process of the material. It is believed that the dispersing performance will be to some extend proportional to the adsorbed amount or the adsorbed surface density and that the cement fineness and the specific surface area of the solid phase present will significantly affect the performance of the SPs [1]. Recently, some studies have shown that the dispersing performance of SPs is also significantly affected by other parameters, such as cement composition and mixing conditions [2, 3].

Even though there are many studies on evaluating SPs from a chemical and rheological point of view, the effect of SPs on controlling setting time and maintaining a rate of compressive strength development is still under discussion [4]. Advances in measurement and computer technologies in recent years have allowed the development of various advanced methods to study the influence of different SPs on the hydration process and formation of structure of cementitious materials. Most of these studies have shown that in conjunction with their well known cement dispersing function, the incorporation of SPs leads to a retardation of the hydration process [5-10] which is attributed to the dispersing action of these admixtures

\footnotetext{
* Corresponding author. Phone: +386 158626 30; fax +38615862601

Email address: grega.trtnik@igmat.eu
} 
in the fresh state [8]. A delay in the setting process of superplasticized cement pastes has been also observed by many different techniques, such as impedance spectroscopy [8], electrical conductivity [11], electrical resistivity [4], and isothermal calorimetry [12, 13].

Using various advanced techniques it was indicated that the incorporation of SP in cement paste clearly influences the morphology and the growth rate of the hydrates [8, 14]. A delay in the formation of portlantide [15] and C-S-H gel $[8,10]$ was observed in the case when different types of SPs were incorporated while the retardation of the formation of ettringite was less distinct [10]. However, after the setting of the cement the incorporation of SPs, while maintaining water/cement ratio, does not affect the mechanical properties of the material significantly $[8,14]$.

Despite many studies, the influence of SPs on the formation of structure of cement based materials is still relatively unclear because details of their working principles lack of a full understanding [15]. Some other advanced methods are therefore recommended to validate and prove these results. Nowadays, ultrasonic wave transmission (USWT) technique has been widely used to evaluate the hydration and microstructure formation process of different cement based materials at early ages. This non-destructive method has been proven to be very sensitive to the well known rules of mix proportioning and other initial characteristics of fresh cement based materials [16-18]. Different methods have been developed to identify initial setting time of cementitious materials based on certain features on the ultrasonic (US) velocity curves [16, 1921]. Although USWT measurements show interesting results, most of these studies have been performed on the materials without admixtures. On the other hand, quantitative study of the sensitivity of this method to detect the influence of admixtures on the hydration and formation of structure of the materials at early ages has been limited. Very recently, Zhu et al. [22] investigated the effects of air voids on US Pwave propagation in early age cement pastes introduced by using air entraining admixtures. US velocity was strongly affected by air voids, resulting in lower values of the P-wave velocity. In the study of Zhang et al. [23] effects of some mineral admixtures (fly ash, slag, and silica fume) on the evolution of the Pwave velocity in cement pastes at early ages were analyzed. It turned out that silica fume addition increased the US P-wave velocity at the very beginning of the hydration process. A reverse phenomenon was observed when fly ash and slag were incorporated. Robeyst et al. studied effects of blast furnace slag on the development of the US energy [24] and US P-wave velocity [25] and indicated that the increase in the US energy and P-wave velocity is generally retarded if ordinary portland cement is replaced by blast furnace slag or fly ash. De Belie et al. [26] presented the possible use of USWT method to analyze the influence of some accelerating admixtures for shotcrete and indicated that US measurement were clearly sensitive to the effect of accelerator type and dosage of the setting behaviour of mortar. A stepwise increase of the accelerator dosage resulted in increasing values of the US velocity at early ages.

\section{Problem interpretation, hypothesis and aim of the research}

Even though the influence of the SPs on the rheological properties and workability is well known, the influence of these admixtures on the formation of structure of cement based materials at early ages is largely unclear. To overcome this inconvenience, new advanced methods are recommended.

According to recent studies, the amount of the solid phase significantly affects the performance of the SPs [1] and the presence of the SPs influences the growth rate of the hydrates [8, 14]. Since US P-wave velocity was found to be directly correlated to the amount of the total and the connected solid phases [2729], the use of the USWT method to detect the influence of SPs on the formation of structure of cementitious materials seems to be a promising method.

The aim of the current research was therefore to investigate the possible use of the USWT method to monitor the formation of structure of cement pastes, influenced by the presence of different types and dosages of SPs. To validate the US results, material temperature was measured in the middle of each test specimen simultaneously to the US measurements. The evolution of the P-wave velocity $\left(v_{\mathrm{P}}\right)$ in time $(t)$ was compared to the evolution of the material temperature $(T)$ in time. 


\section{Experimental study}

\subsection{Experimental methods}

\subsubsection{US wave transmission measurements}

US P-wave transmission measurements were performed using new commercially available instrument and a special software which shows a received US signal and the P-wave velocity $\left(v_{\mathrm{P}}\right)$ in a real time during the experiment. The apparatus consists of a waveform generator board and two piezoelectric broadband transducers of central frequency $150 \mathrm{kHz}$ and $25 \mathrm{~mm}$ in diameter. Within this study, a driving voltage and a pulse signal width were $500 \mathrm{~V}$ and $3.3 \mu$ s, respectively. All subsequent measurements were taken and stored automatically every $1 \mathrm{~min}$, resulting into a $v_{\mathrm{P}}-t$ curves for each analyzed cement paste mixture. The transducers were pushed into the slurry to a depth of $5 \mathrm{~mm}$ to enable full contact between the sensors and the specimen. Petroleum jelly was used as a couplant to enhance contact between the transducers and the material. All measurements continued for approximately 24 hours after mixing cement pastes. A schematic representation of the experimental setup is presented in Fig. 1.

a)

b)
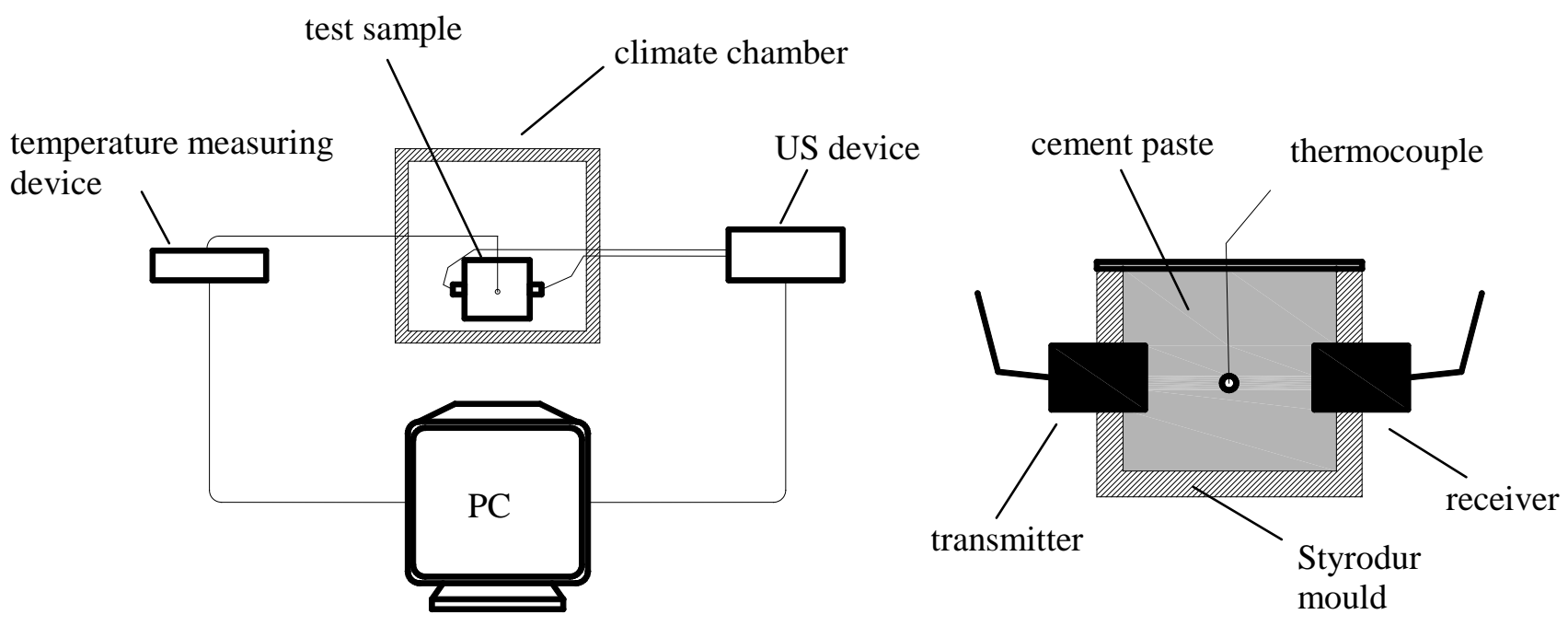

Figure 1 a) Schematic presentation of the test setup, b) schematic representation of the test sample.

\subsubsection{Temperature measurements}

To validate and substantiate the US results, evolution of the material temperature $(T)$ in time was also measured by a previously calibrated thermocouple embedded in the cement paste at the centre of the specimen (Fig. 1). All US and temperature measurements were carried out simultaneously on the same test specimens which is of great importance to maintain the same material characteristics and curing conditions. The temperature data were taken and stored automatically every $1 \mathrm{~min}$, resulting into a $T-t$ curve for each analyzed cement paste mixture.

\subsection{Materials and specimen preparation}

\subsubsection{Basic materials}

The cements used in the investigation were Type I ordinary Portland cements with the characteristics, presented in Table 1. CC and BS in the table stand for the clinker content and Blaine surface of each cement, respectively. The calculated Bogue compositions of these cements (mass fractions) were deduced from a chemical characterization. It can be seen from Table 1 that the cements differ mainly in their fineness. 
Table 1 Basic characteristics of the cements used in the study.

\begin{tabular}{cccccccc}
\hline Cement label & Cement type & CC [\%] & BS [cm $/ \mathrm{g}]$ & $\mathrm{C}_{3} \mathrm{~S}[\%]$ & $\mathrm{C}_{2} \mathrm{~S}[\%]$ & $\mathrm{C}_{3} \mathrm{~A}[\%]$ & $\mathrm{C}_{4} \mathrm{AF}[\%]$ \\
\hline $\mathrm{C} 1$ & CEM I 42,5 N & $>95$ & 2640 & 60.2 & 13.6 & 7.2 & 9.3 \\
$\mathrm{C} 2$ & CEM I 52,5 R & $>95$ & 4310 & 57.7 & 13.0 & 6.9 & 8.9 \\
\hline
\end{tabular}

The influence of SPs on the $v_{\mathrm{P}}-t$ curves was analyzed for four types of commercially available admixtures. Two sulfonate naphthalene-formaldehyde (hereinafter denoted as SP1 and SP2) and two comb-shaped polycarboxylate ether (PCE1 and PCE2) SPs were used in this study. In Table 2, some basic characteristics of these SPs are presented where $\rho_{20}, \mathrm{AS}, \mathrm{pH}, \mathrm{ACl}^{-}$, and AA stand for the relative density at $20^{\circ} \mathrm{C}$, conventional dry materials content, $\mathrm{pH}$ value, water soluble chloride content, and alkali content ( $\mathrm{Na}_{2} \mathrm{O}$ equivalent), respectively. Labels $\mathrm{L}$ and $\mathrm{H}$ in the table stand for the minimum and maximum dosage of each SP, recommended by the manufacturer, respectively.

Table 2 Basic characteristics of the superplasticizers used in the study.

\begin{tabular}{lccccccc}
\hline SP label & $\begin{array}{c}\rho_{20} \\
{\left[\mathrm{~kg} / \mathrm{dm}^{3}\right]}\end{array}$ & $\begin{array}{c}\mathrm{AS} \\
{[\%]}\end{array}$ & $\begin{array}{c}\mathrm{pH} \\
{[-]}\end{array}$ & $\begin{array}{c}\mathrm{ACl}^{-} \\
{[\%]}\end{array}$ & $\begin{array}{c}\mathrm{AA} \\
{[\%]}\end{array}$ & $\begin{array}{c}\mathrm{L} \\
{[\%]}\end{array}$ & $\begin{array}{c}\mathrm{H} \\
{[\%]}\end{array}$ \\
\hline SP1 & $1.13 \pm 0.03$ & $22.5 \pm 1.1$ & $6.5 \pm 1$ & 0 & $<6.5$ & 1.0 & 4.0 \\
SP2 & $1.08 \pm 0.02$ & $18.5 \pm 1.8$ & $9.0 \pm 1$ & 0 & $<4.0$ & 1.0 & 3.0 \\
PCE1 & $1.06 \pm 0.02$ & - & $6.2 \pm 1$ & 0 & $<3.0$ & 0.6 & 2.0 \\
PCE2 & $1.05 \pm 0.02$ & - & $3.0 \pm 1$ & 0 & $<3.0$ & 0.2 & 1.0 \\
\hline
\end{tabular}

\subsubsection{Specimen preparation and cement paste mixtures}

The specimens were mixed according to EN 196-1 standard [30] and incorporated into a 50x50x50 mm extruded rigid polystyrene foam (Stirodur) mould with high damping properties, suppressing US waves from travelling through the mould at the very beginning of the hydration process [26]. Two parts of the experimental work were performed to achieve the objective of this study. During the first part, sixteen different cement pastes were prepared according to the proportions shown in Table 3a. Within the second part, eleven additional cement pastes were prepared aimed to analyze some interesting phenomena that appeared during the first part of the research project (see Table 3b). All the pastes are labelled according to the type and dosage of the SP that they contain. Along with the superplasticized cement pastes, three reference pastes were also prepared without any admixture. All the tests were conducted in a temperature controlled chamber at $21 \pm 1^{\circ} \mathrm{C}$ and $60 \pm 5 \%$ relative humidity (see Fig. 1a). 
Table 3 Mixture proportions used in the study - values in brackets stand for the dosage of each SP with respect to the amount of cement, a) first part, b) second part.

a)

\begin{tabular}{lccc}
\hline $\begin{array}{l}\text { Cement paste } \\
\text { label }\end{array}$ & $\begin{array}{c}\text { W/C } \\
{[-]}\end{array}$ & $\begin{array}{c}\text { Cement } \\
\text { type }\end{array}$ & $\begin{array}{c}\text { SP type } \\
{[\%]}\end{array}$ \\
\hline R1/C1/0.30 & 0.30 & C1 & $-(-)$ \\
R2/C1/0.40 & 0.40 & C1 & $-(-)$ \\
R3/C2/0.40 & 0.40 & C2 & $-(-)$ \\
\hline SP1/1.0 & 0.30 & C1 & SP1 $(1.0 \%)$ \\
SP1/2.0 & 0.30 & C1 & SP1 $(2.0 \%)$ \\
SP1/3.0 & 0.30 & C1 & SP1 $(3.0 \%)$ \\
SP1/4.0 & 0.30 & C1 & SP1 $(4.0 \%)$ \\
\hline SP2/1.0 & 0.30 & C1 & SP2 $(1.0 \%)$ \\
SP2/2.0 & 0.30 & C1 & SP2 $(2.0 \%)$ \\
SP2/3.0 & 0.30 & C1 & SP2 $(3.0 \%)$ \\
\hline PCE1/0.2 & 0.30 & C1 & PCE1 $(0.2 \%)$ \\
PCE1/0.5 & 0.30 & C1 & PCE1 $(0.5 \%)$ \\
PCE1/1.0 & 0.30 & C1 & PCE1 $(1.0 \%)$ \\
\hline PCE2/0.6 & 0.30 & C1 & PCE2 $(0.6 \%)$ \\
PCE2/1.3 & 0.30 & C1 & PCE2 $(1.3 \%)$ \\
(C1/0.30) & & C1 & PCE2 $(2.0 \%)$ \\
PCE2/2.0 & 0.30 & &
\end{tabular}

b)

\begin{tabular}{lccc}
\hline $\begin{array}{l}\text { Cement paste } \\
\text { label }\end{array}$ & $\begin{array}{c}\text { w/c } \\
{[-]}\end{array}$ & $\begin{array}{c}\text { Cement } \\
\text { type }\end{array}$ & $\begin{array}{c}\text { SP type } \\
{[\%]}\end{array}$ \\
\hline C1/0.20 & 0.20 & C1 & PCE2 $(1.3 \%)$ \\
C1/0.25 & 0.25 & C1 & PCE2 $(1.3 \%)$ \\
C1/0.35 & 0.35 & C1 & PCE2 $(1.3 \%)$ \\
C1/0.40 & 0.40 & C1 & PCE2 $(1.3 \%)$ \\
\hline C2/0.30 & 0.30 & C2 & PCE2 $(1.3 \%)$ \\
$(\mathrm{C} 2 / 0.30 / 1.3)$ & & & PCE2 $(1.3 \%)$ \\
C2/0.35 & 0.35 & C2 & P2/0.40 \\
(C2/0.40/1.3) & 0.40 & C2 & PCE2 $(1.3 \%)$ \\
\hline C2/0.30/0.6 & 0.30 & C2 & PCE2 $(0.6 \%)$ \\
C2/0.30/2.0 & 0.30 & C2 & PCE2 $(2.0 \%)$ \\
\hline C2/0.40/0.6 & 0.40 & C2 & PCE2 $(0.6 \%)$ \\
C2/0.40/2.0 & 0.40 & C2 & PCE2 $(2.0 \%)$ \\
\hline
\end{tabular}

\section{Experimental results}

\subsection{Part 1}

\subsubsection{Definition of stages in the evolution of P-wave velocity}

Fig. 2a shows a typical evolution of the $v_{\mathrm{p}}-t$ and $T-t$ curves for the cement paste mixture during the first 24 hours. Analogically, a typical evolution of the rate (time derivative) of $v_{\mathrm{P}}\left(\mathrm{d} v_{\mathrm{P}}\right)$ and rate of $T(\mathrm{~d} T)$ in time is presented in Fig. 2b. Five stages are indicated on the $v_{\mathrm{P}}-t$ curves which have been already explained by the authors in a previous publication [17]. However, to properly track the focus of this article, a short explanation of the stages is performed and related to the evolution of the $T-t$ and $\mathrm{d} T-t$ curves.

At stage 1, no signal (and consequently no $v_{\mathrm{P}}$ ) is observed because of high attenuation caused by air voids entrapped in the material [31]. At the beginning of the second stage, a relatively low initial value of $v_{\mathrm{P}}$ is evident from Fig. 2a closed to the value of $v_{P}$ in air (i.e. $340 \mathrm{~m} / \mathrm{s}$ ). This phenomenon has been already reported by Sayers and Dahlin [31] and has been also proven by other researchers [25, 27, 28, 32-35]. During the second stage the first increase in the $v_{\mathrm{P}}$ is observed which is not attributed to setting but to the formation of ettringite [17, 33]. On the contrary, no significant increase in the temperature can be observed during the first part of the second stage. This stage extends up to the time $t_{\mathrm{vPI} 1}$ of the first inflection point $v_{\mathrm{P} 11}$ on the $\mathrm{d} v_{\mathrm{P}}-t$ curve (Fig. 2b). The $t_{\mathrm{vP} 11}$ time corresponds very well to the time when the $v_{\mathrm{P}}$ reaches the $v_{\mathrm{P}}$ in water $(1450 \mathrm{~m} / \mathrm{s})$ which was found to be a good estimation of the initial setting time of cement pastes [16, 33]. However, this conclusion is not valid for cement pastes with entrained air voids [22].

During the third stage, both $v_{\mathrm{P}}$ and $T$ increase significantly, indicating a period of an intensive hydration. This acceleration stage extends up to the time $t_{\mathrm{vPI} 2}$ of the second inflection point $v_{\mathrm{PI} 2}$ on the $\mathrm{d} v_{\mathrm{P}}-t$ curve at 
which the intensive development of the connected solid phase [18], causing a fast increase in speed of sound, begins to slow down (Fig. 2b). It can be seen from Fig. $2 \mathrm{~b}$ that the time of the second inflection point $t_{\mathrm{VPI} 2}$ corresponds very well to the time $t_{T 11}$ when the first inflection point $T_{\mathrm{I} 1}$ appears on the $\mathrm{d} T-t$ curve. This important observation indicates that both $v_{\mathrm{P}}$ and $T$ reach their maximum rate at the same hydration time which will be analyzed further later in the article.

Next, stage four is extending to the time when a plateau (stage 5) on the $v_{\mathrm{P}}-t$ curves is reached. This corresponds well to the time $t_{T 12}$ of the second inflection point $T_{\mathrm{I} 2}$ on the $\mathrm{d} T-t$ curves (Fig. 2a). Hereinafter, labels $b_{2}, b_{3}\left(\equiv t_{\mathrm{vPI} 1}\right), b_{4}\left(\equiv t_{\mathrm{vPI} 2}\right)$, and $b_{5}$ are used to define the beginning of the stage $2,3,4$, and 5, respectively.

a)

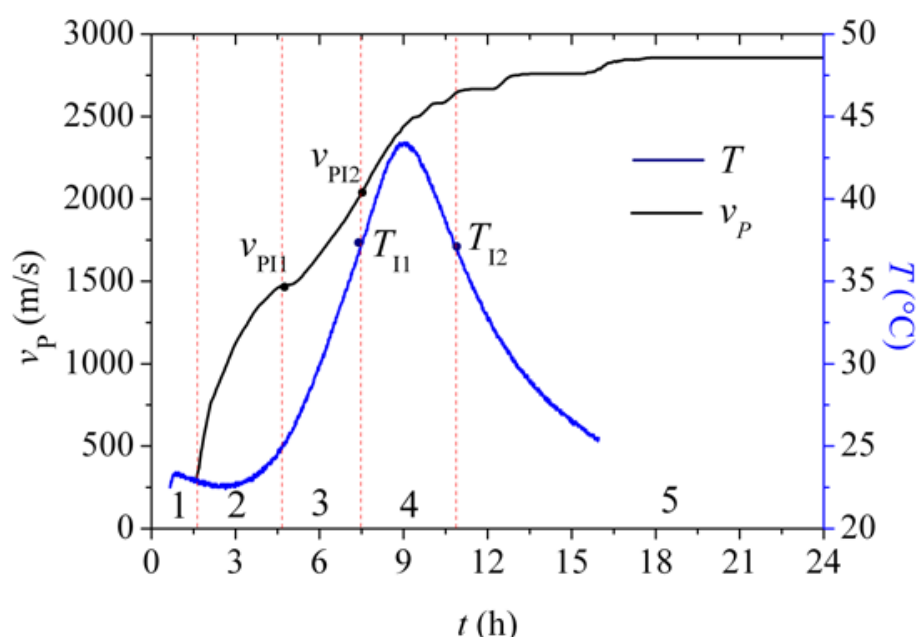

b)

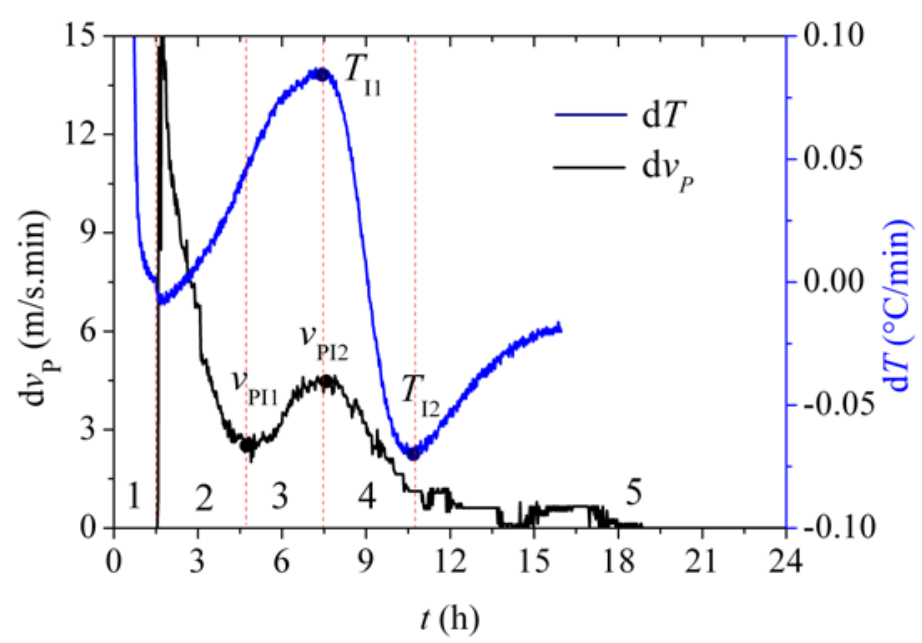

Figure 2 Definition of five stages during the evolution of the P-wave velocity through cement pastes,

a) $v_{\mathrm{P}}-t$ and $T-t$ curves, b) $\mathrm{d} v_{\mathrm{P}}-t$ and $\mathrm{d} T-t$ curves.

\subsubsection{Reproducibility and reliability of the results}

Three different reference cement pastes without admixtures were prepared three times and US measurements were performed on each mixture to analyze the reproducibility of the method and apparatus (see Fig. 3). As expected, mixtures with lower w/c ratio and higher cement fineness show higher $v_{\mathrm{P}}$ values. This can be attributed to a higher volume and higher specific surface area of the total and the connected solid phase in the case of lower w/c ratio and higher cement fineness $[16,18]$. Singlefactor analysis of variance (ANOVA) was performed to study the reliability of the determination of the $b_{2}, b_{3}, b_{4}$, and $b_{5}$ values. For this purpose, a set of null hypothesis, $H_{0}$, and corresponding alternatives, $H_{\mathrm{A}}$, was defined as follows $(i=2, \ldots, 5)$ :

$H_{0 \mathrm{i}}$ : $\quad$ cement paste composition has no influence on the $b_{\mathrm{i}}$ values,

$H_{\mathrm{Ai}}$ : cement paste composition has an influence on the $b_{\mathrm{i}}$ values. 
a)

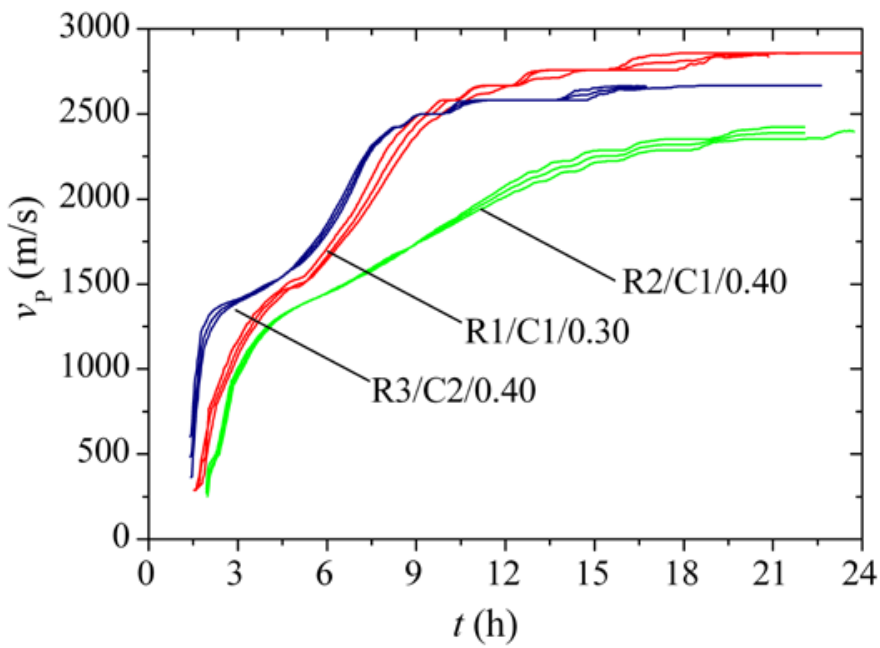

b)

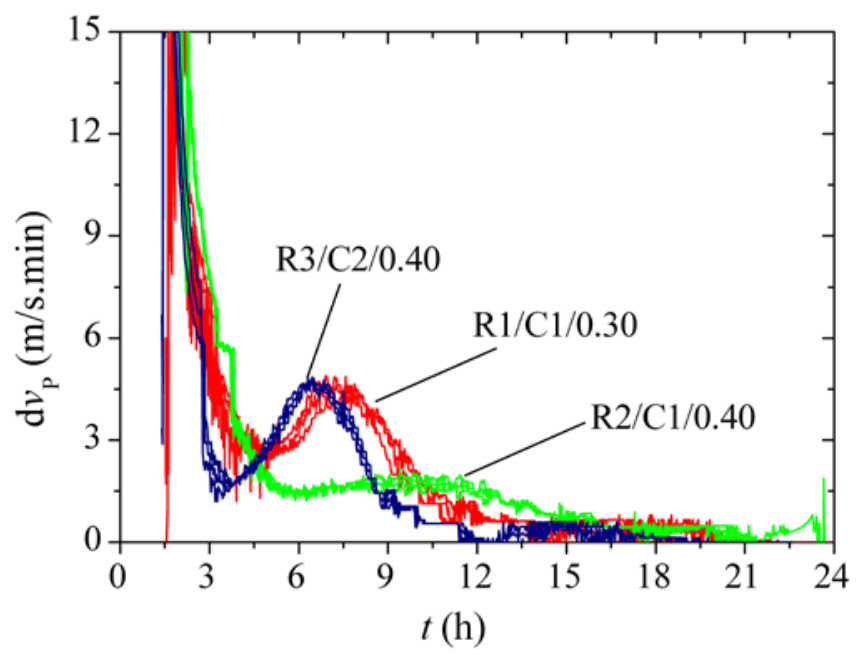

Figure 3 Reproducibility of the US P-wave transmission measurements,

a) P-wave velocity, b) rate of P-wave velocity.

A theoretical description of the ANOVA and hypothesis testing methods can be find elsewhere (for example [36]). In Table 4 , the $b_{2}, b_{3}, b_{4}$, and $b_{5}$ values for all reference mixtures are summarized. $F$ stands for the $F$ test statistic, evaluated as a ratio between mean square between groups $\left(M S_{\mathrm{B}}\right)$ and mean square within groups $\left(M S_{\mathrm{W}}\right)$ while $F_{\text {crit }}$ stands for a critical value of $F$, determined according to a significance level $\alpha$ which is chosen in advance.

Table 4 ANOVA for values of $b_{2}, b_{3}, b_{4}$, and $b_{5}$ with respect to different mixtures.

\begin{tabular}{|c|c|c|c|c|c|c|c|c|c|c|c|c|}
\hline \multirow{2}{*}{$\begin{array}{l}\text { cement paste } \\
\text { label }\end{array}$} & \multicolumn{3}{|c|}{$b_{2}[\mathrm{~min}]$} & \multicolumn{3}{|c|}{$b_{3}[\mathrm{~min}]-t_{v \mathrm{PI} 1}$} & \multicolumn{3}{|c|}{$b_{4}[\mathrm{~min}]-t_{\mathrm{vPI} 2}$} & \multicolumn{3}{|c|}{$b_{5}[\mathrm{~min}]$} \\
\hline & 1 & 2 & 3 & 1 & 2 & 3 & 1 & 2 & 3 & 1 & 2 & 3 \\
\hline R1/C1/0.30 & 92 & 91 & 92 & 280 & 285 & 287 & 450 & 440 & 445 & 800 & 790 & 780 \\
\hline $\mathrm{R} 2 / \mathrm{C} 1 / 0.40$ & 110 & 114 & 120 & 360 & 355 & 360 & 590 & 600 & 605 & 1070 & 1075 & 1080 \\
\hline R3/C2/0.40 & 83 & 83 & 85 & 210 & 220 & 225 & 380 & 385 & 394 & 710 & 690 & 705 \\
\hline$F$ & \multicolumn{3}{|c|}{86.33} & \multicolumn{3}{|c|}{554.26} & \multicolumn{3}{|c|}{806.82} & \multicolumn{3}{|c|}{1468.32} \\
\hline$F_{\text {crit }}(\alpha=0.01)$ & \multicolumn{3}{|c|}{10.92} & \multicolumn{3}{|c|}{10.92} & \multicolumn{3}{|c|}{10.92} & \multicolumn{3}{|c|}{10.92} \\
\hline
\end{tabular}

When $F>F_{\text {crit, }}$, the null hypothesis $H_{0 \mathrm{i}}(\mathrm{i}=2, \ldots, 5)$ is rejected following that the cement paste composition has a statistically significant influence on the $b_{\mathrm{i}}$ values. Consequently, the differences between $b_{\mathrm{i}}$ values, resulting from the three repetitions of each mixture, are much smaller when compared to the differences between these values for different cement paste mixtures. Table 4 indicates that the values of the test statistic $F$ are larger than the critical value $F_{\text {crit, }}$, determined at the $\alpha=0.01$. This statement turned out to be true for all $b$ values indicating that these values depend on the mixture type significantly. Based on these results, high repeatability of the $v_{\mathrm{P}}-t$ curves was established.

\subsubsection{Influence of SP types and dosages on the $v_{\mathrm{P}}-t$ curves}

The changes of $v_{\mathrm{P}}$ in time for cement paste mixtures including different types and dosages of SPs are presented in Fig. 4. 
a)

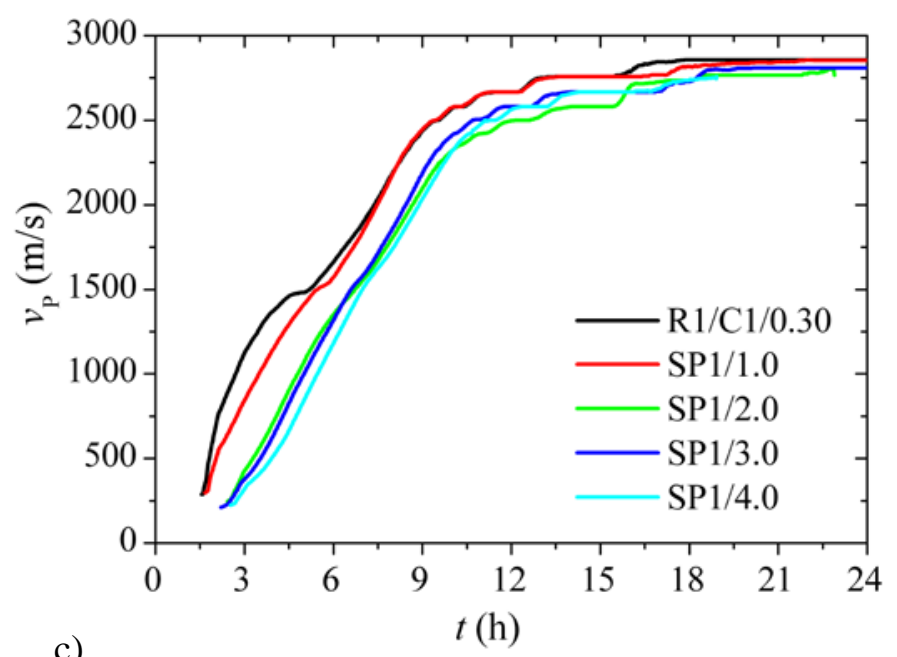

c)

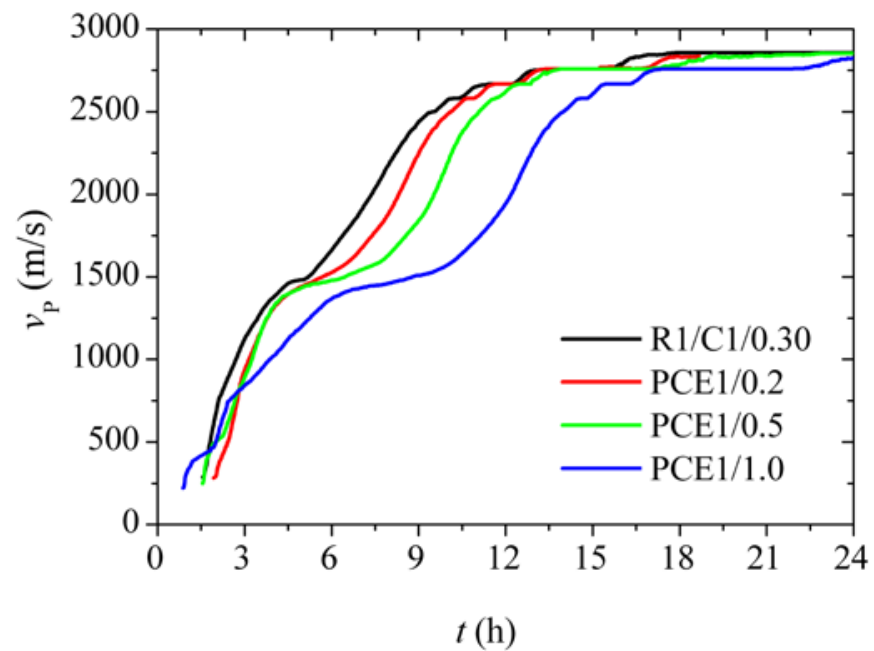

b)

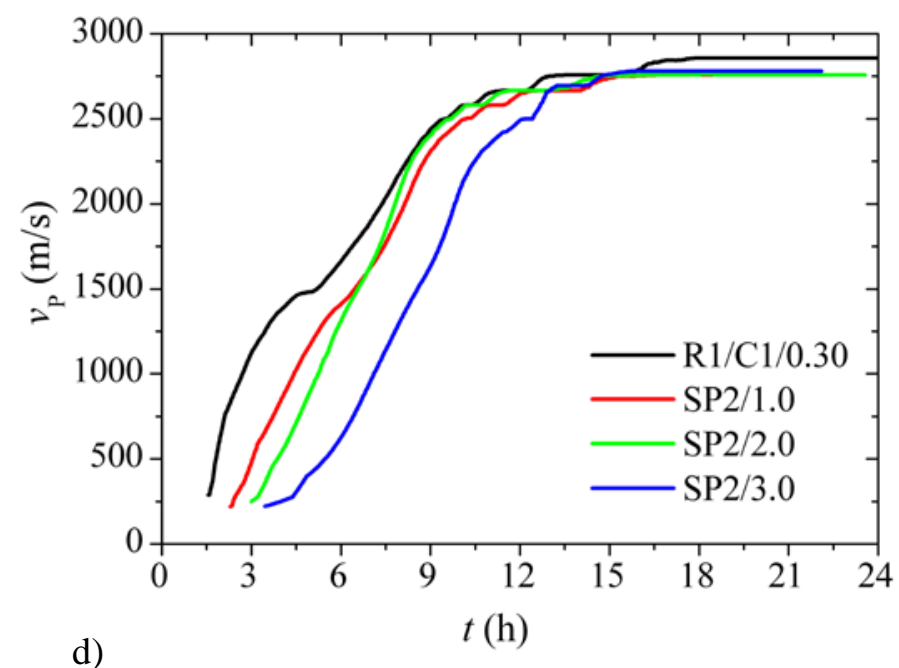

d)

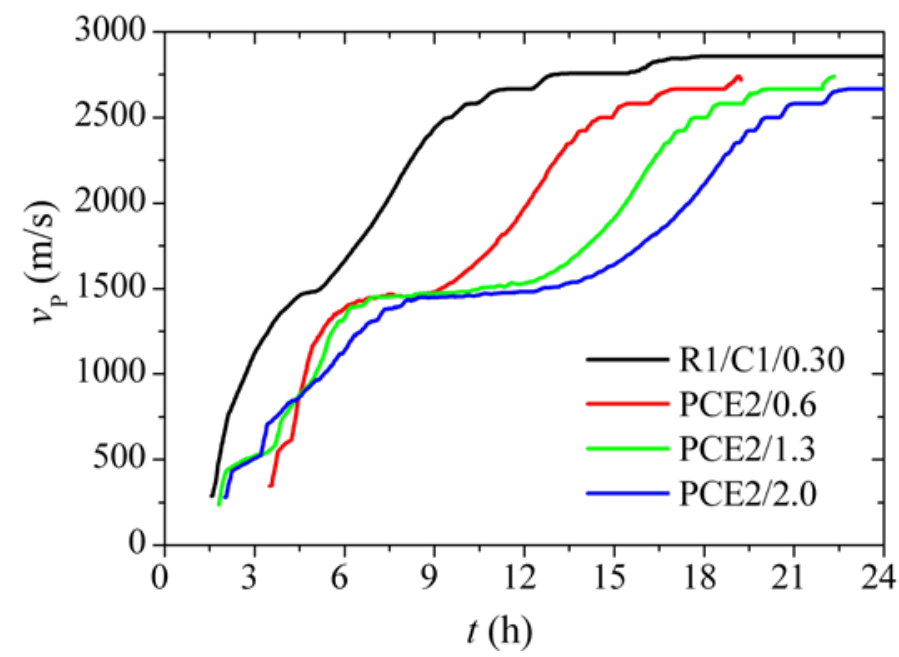

Figure 4 Development of the $v_{\mathrm{P}}-t$ curves during the first 24 hours, influenced by a) SP1, b) SP2 c) PCE1, d) PCE2 admixtures.

Different shapes of the $v_{\mathrm{P}}-t$ curves are evident from Fig. 4 originating from the presence of different types and dosages of SPs. Comparing to the reference cement paste, a delay in the evolution of the $v_{\mathrm{P}}-t$ curves is clearly evident in the case of superplasticized mixtures. As expected, this delay increases with the increasing dosage of the admixtures and is also more pronounced when both PCE types of SPs are used. Consequently, the durations of the second (dormant) and third (acceleration) stages on the $v_{\mathrm{P}}-t$ curves are influenced by the presence of different types and dosages of SPs importantly, which is clearly presented in Fig. 5. When compared to the reference mixture (R1/C1/0.30), an increase in the duration of the second stage is observed from Fig. 5a in the case of superplasticized cement pastes. Even though the duration of the second stage increases almost linearly with increasing dosage of each SP, this is more pronounced in the case when both PCEs were incorporated. Interestingly, a linear decrease in the length of the third stage is evident from Fig. 5b when the sulfonate naphthalene-formaldehyde types of SP (SP1, SP2) were used and on the contrary, the presence of both PCEs increases the length of the third stage significantly. This can be attributed mostly to a distinctively slow increase in the $v_{\mathrm{P}}$ which occurs approximately at the time when the $v_{\mathrm{P}}$ reaches the value of $1450-1500 \mathrm{~m} / \mathrm{s}$, corresponding to the $v_{\mathrm{P}}$ in water (refer to Fig. 4c and Fig. 4d). Even though this plateau can be clearly observed in the case when both PCEs were incorporated, it is longer when the PCE2 admixture is used and extends with the increasing dosage of the admixture (compare Figs. 4c and 4d). A relatively long period of slow increase in $v_{\mathrm{P}}$ at the $v_{\mathrm{P}}$ level of 1450-1500 m/s in the case when both PCEs are incorporated is one of the central observations of the study and is discussed in more detail later in the article. 
a)

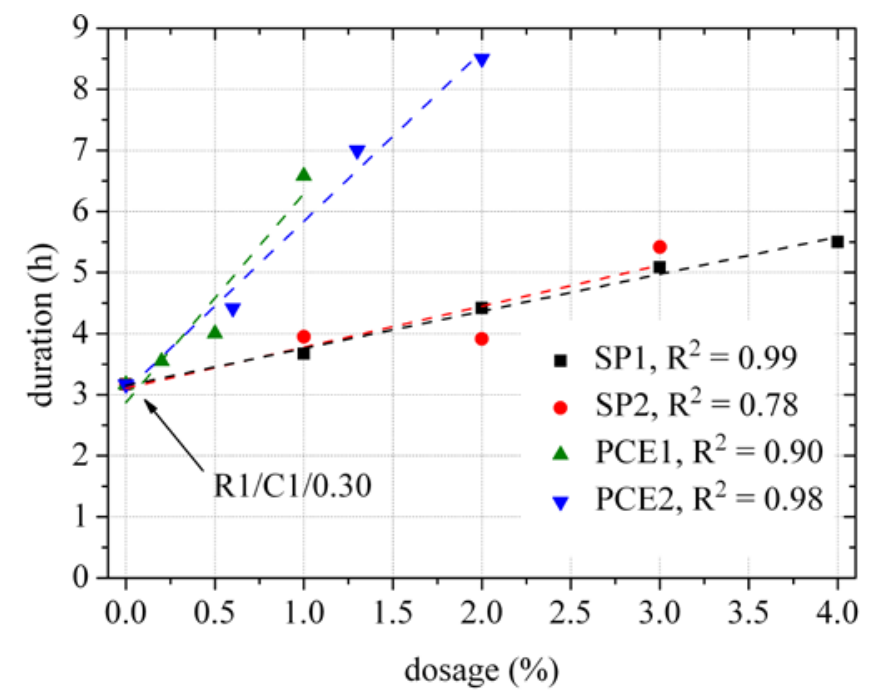

b)

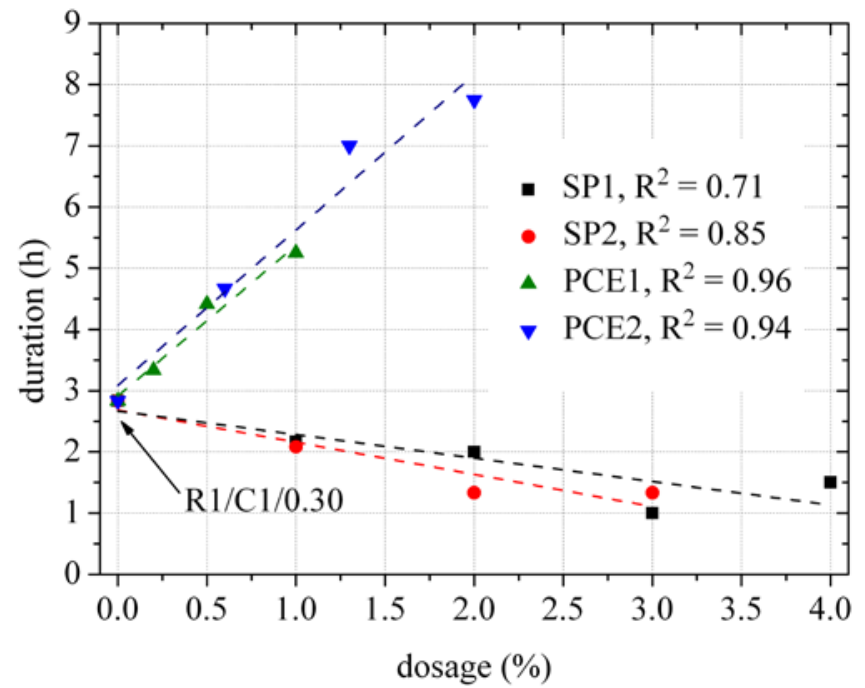

Figure 5 Influence of the type and dosage of SPs on the duration of the $2^{\text {nd }}$ and $3^{\text {rd }}$ stage on the $v_{\mathrm{P}}-t$ curves, a) stage 2, b) stage 3.

In Table 5, the $b$ times together with the $v_{v \mathrm{PI} 1}$ and $v_{v \mathrm{PI} 2}$ values, corresponding to the $b_{3}\left(\equiv t_{\mathrm{vPI} 1}\right)$ and $b_{4}$ (三 $\left.t_{\mathrm{vPI} 2}\right)$ characteristic times, respectively, are summarized with respect to the type and dosage of each SP. A stepwise increase of the SP dosage results in increasing $b_{3}, b_{4}$, and $b_{5}$ times, indicating that $v_{\mathrm{PI} 1}$ and $v_{\mathrm{PI} 2}$ inflection points occur later in the case when different types and dosages of each SP are incorporated in the material. Again, these delays are more pronounced when both types of PCEs were used.

Table 5 Influence of the SP dosage on the beginning of the stages on the $v_{\mathrm{P}}-t$ curves. The values in brackets stand for the relative difference with respect to the reference R1/C1/0.30 cement paste.

\begin{tabular}{|c|c|c|c|c|c|c|}
\hline $\begin{array}{l}\text { mixture } \\
\text { label }\end{array}$ & $\begin{array}{c}b_{2} \\
{[\min (\%)]}\end{array}$ & $\begin{array}{c}b_{3}\left(t_{\mathrm{vP} 11}\right) \\
{[\min (\%)]}\end{array}$ & $\begin{array}{c}b_{4}\left(t_{v \mathrm{PP} 2}\right) \\
{[\min (\%)]}\end{array}$ & $\begin{array}{c}b_{5} \\
{[\min (\%)]}\end{array}$ & $\begin{array}{c}v_{v \mathrm{PI} 1} \\
{[\mathrm{~m} / \mathrm{s}(\%)]}\end{array}$ & $\begin{array}{c}v_{v \mathrm{P} 2} \\
{[\mathrm{~m} / \mathrm{s}(\%)]}\end{array}$ \\
\hline R1/C1/0.30 & 90 & 280 & 450 & 800 & $1460(-)$ & $2050(-)$ \\
\hline SP1/1.0 & $100(11.1)$ & 320 (14.3) & $450(0.0)$ & 810 (1.3) & $1470(0.7)$ & $2010(-1.9)$ \\
\hline SP1/2.0 & $135(50.0)$ & 400 (42.9) & 520 (15.6) & $840(5.0)$ & 1485 (1.7) & $1995(-2.7)$ \\
\hline SP1/3.0 & $135(50.0)$ & $440(57.1)$ & $500(11.1)$ & 850 (6.3) & $1490(2.0)$ & $1960(-4.4)$ \\
\hline SP1/4.0 & $120(33.3)$ & $450(60.7)$ & $540(20.0)$ & $880(10.0)$ & $1550(6.2)$ & $2005(-2.2)$ \\
\hline SP2/1.0 & 133 (47.8) & 370 (32.1) & $495(10.0)$ & 830 (3.8) & $1440(-1.4)$ & $2030(-1.0)$ \\
\hline SP2/2.0 & 155 (72.2) & 390 (39.3) & $470(4.4)$ & 900 (12.5) & $1460(0.0)$ & $1995(-2.7)$ \\
\hline SP2/3.0 & 175 (94.4) & $500(78.6)$ & 580 (28.9) & $920(15.0)$ & $1430(-2.1)$ & $1960(-4.4)$ \\
\hline PCE1/0.2 & $112(24.4)$ & 325 (16.1) & 525 (16.7) & $805(0.6)$ & $1450(-0.7)$ & 2190 (6.8) \\
\hline PCE1/0.5 & $90(0.0)$ & 330 (17.9) & 595 (32.2) & $1010(26.3)$ & $1450(-0.7)$ & $2190(6.8)$ \\
\hline PCE1/1.0 & $50(-44.4)$ & 445 (58.9) & 760 (68.9) & 1070 (33.8) & $1480(1.37)$ & 2190 (6.8) \\
\hline PCE2/0.6 & 205 (127.8) & 470 (67.9) & 750 (66.7) & $1020(27.5)$ & $1450(-0.7)$ & 2170 (5.8) \\
\hline PCE2/1.3 & 105 (16.7) & 525 (87.5) & 945 (110.0) & $1200(50.0)$ & $1455(-0.3)$ & 2180 (6.3) \\
\hline PCE2/2.0 & 115 (27.8) & 625 (123.2) & $1090(142.2)$ & $1390(73.8)$ & $1450(-0.7)$ & $2170(5.8)$ \\
\hline
\end{tabular}


However, the $v_{\mathrm{P}}$ values, corresponding to the first inflection point $v_{\mathrm{P} 11}$ on $v_{\mathrm{P}}-t$ curves are quite similar for all cement paste mixtures regardless of the type and dosage of SPs (see Table 5). The first inflection points occur when the $v_{\mathrm{P}}$ reaches a value of approximately $1450 \mathrm{~m} / \mathrm{s}$, corresponding to the value of $v_{\mathrm{P}}$ in water, which has been already discussed in the literature in the case of pure cement paste mixtures without admixtures [16]. The presence of different types and dosages of SPs in the cement paste composition does not influence this phenomenon. Similar $v_{\mathrm{P}}$ values are also evident from Table 5 in the case when $v_{\mathrm{PI} 2}$ points are taken into account. Moreover, it can be seen from Fig. 4 that a long-term $v_{\mathrm{P}}$ value during the $5^{\text {th }}$ stage is very similar for all analyzed cement paste mixtures, regardless of the type and dosage of the SPs. These phenomena indicate that the type and dosage of the SP have no effect on the final amount of the total and the connected solid phase developed during the formation of structure of the materials.

In summary, the development of the $v_{\mathrm{P}}$ in time shows that the incorporation of the SP admixtures inevitably retard formation of structure and setting phenomena of cement pastes. This further substantiates the results reported by other authors, when some other advanced techniques have been used [5-13]. PCE admixtures used in the study retard the solid network frame development more intensively especially during the setting period of the hydration process, resulting in the clearly evident plateau on the $v_{\mathrm{P}}-t$ curves at this hydration period. This interesting phenomenon is analyzed further during the second part of the experimental work.

\subsection{Part 2}

\subsubsection{Determination of the plateau length}

To analyze the appearance of the plateau on the $v_{\mathrm{P}}-t$ curves in the case of the PCE incorporation in more detail, several additional cement paste mixtures were prepared with the objective to study the influence of the PCE dosage and cement paste composition on the plateau length (see Table 3b). The length of the plateau was determined on the basis of three straight lines tangent to the $v_{\mathrm{P}}-t$ curves and labelled as $d_{\mathrm{p}}$ in this study (Fig. 6). Since the plateau was more evident in the cases when PCE2 admixture was added (refer to Fig. 4), this type of PCE was used in the following study.

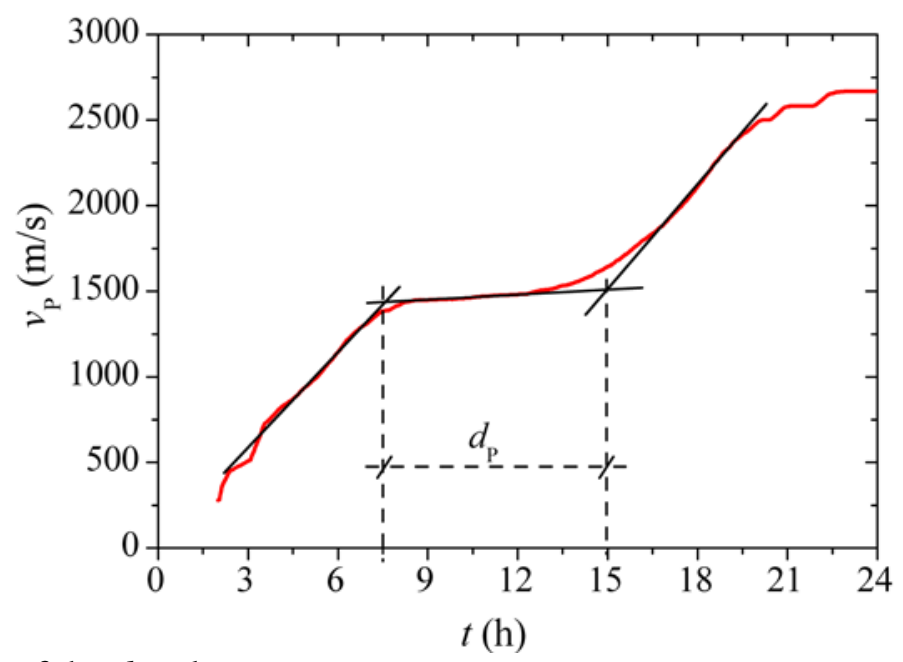

Figure 6 Determination of the $d_{\mathrm{p}}$ value.

\subsubsection{Influence of the PCE dosage and cement paste composition on the plateau length}

The influence of the PCE dosage on the plateau length is presented in Fig. 7 for cement pastes with different cement types and w/c ratios. As an addition, the $v_{\mathrm{P}}-t$ curve for the corresponding reference mixture is also presented in Figs. 7a and 7c and for clarity, a corresponding inset graph showing a duration of the plateau is included in each parent graph. As indicated before, in all cases, the increase of the PCE dosage results in increase of the plateau length. 
a)

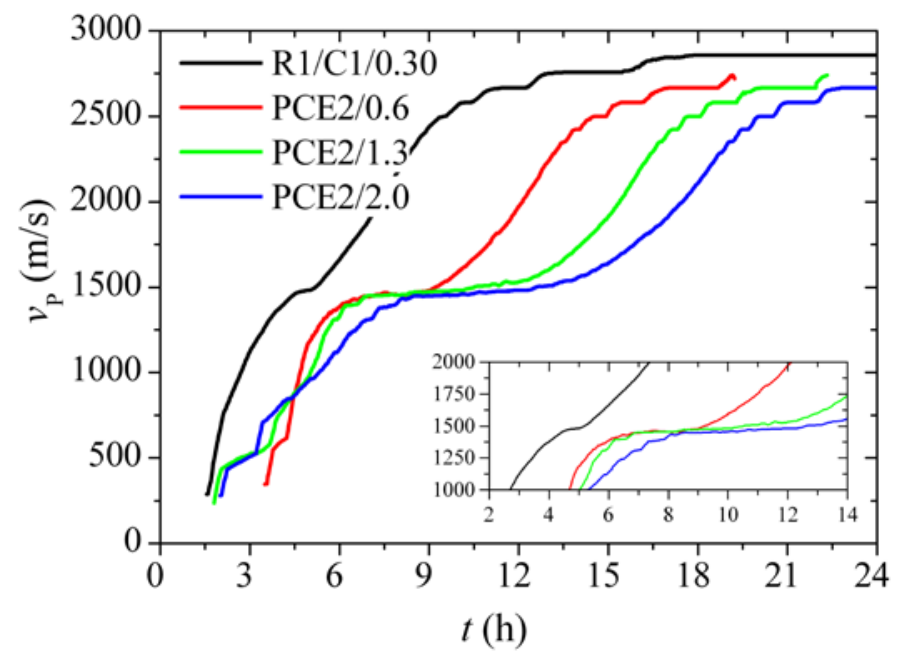

b)

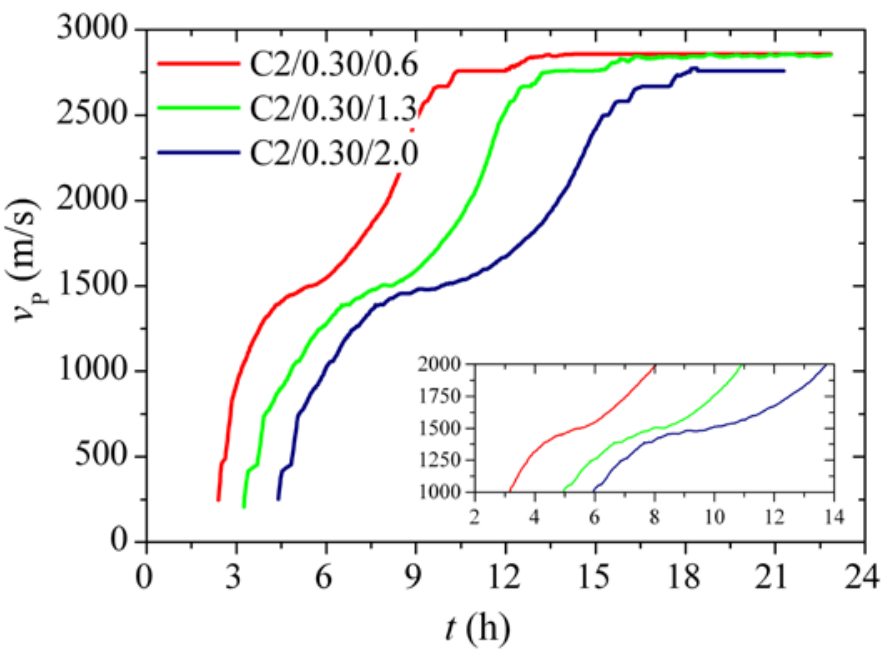

c)

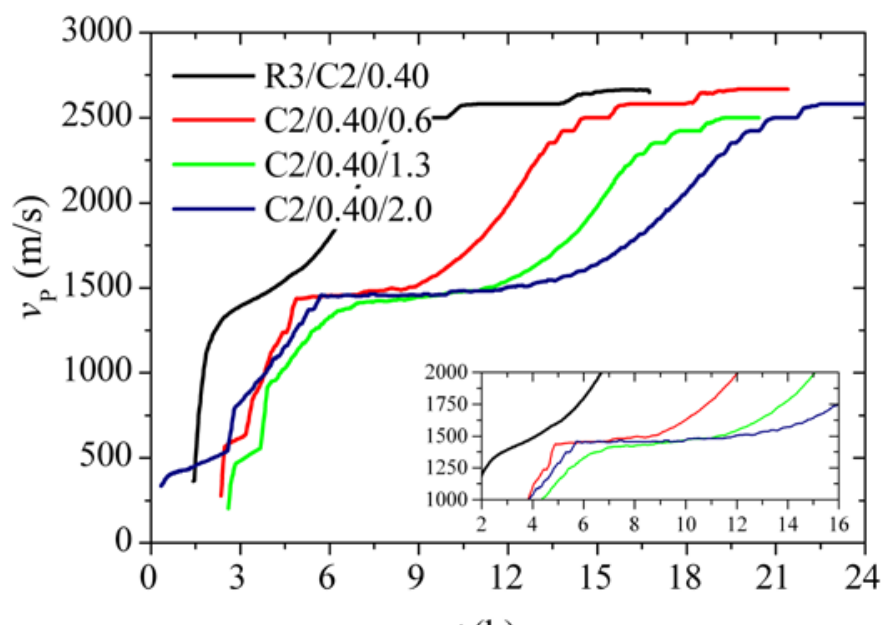

$t(\mathrm{~h})$

Figure 7 Influence of the PCE2 dosage on the development of the $v_{\mathrm{P}}-t$ curves during the first 24 hours,

a) $\left.\left.\mathrm{C} 1, \mathrm{w} / \mathrm{c}=0.30, \mathrm{BS}=2640 \mathrm{~cm}^{2} / \mathrm{g}, \mathrm{b}\right) \mathrm{C} 2, \mathrm{w} / \mathrm{c}=0.30, \mathrm{BS}=4310 \mathrm{~cm}^{2} / \mathrm{g}, \mathrm{c}\right) \mathrm{C} 2, \mathrm{w} / \mathrm{c}=0.40, \mathrm{BS}=4310$ $\mathrm{cm}^{2} / \mathrm{g}$.

From Fig. 8, the influence of the w/c ratio and cement fineness on the development of the $v_{\mathrm{P}}-t$ curves in the case of superplasticized cement pastes (1.3\% PCE2) can be observed. It can be seen that the plateau length increases with the increasing w/c ratio importantly. 
a)

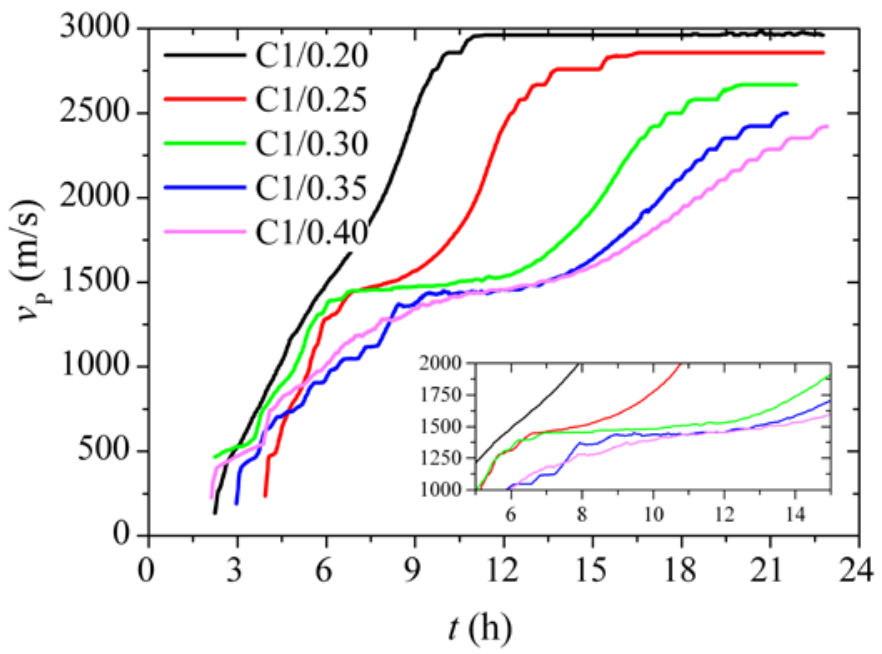

b)

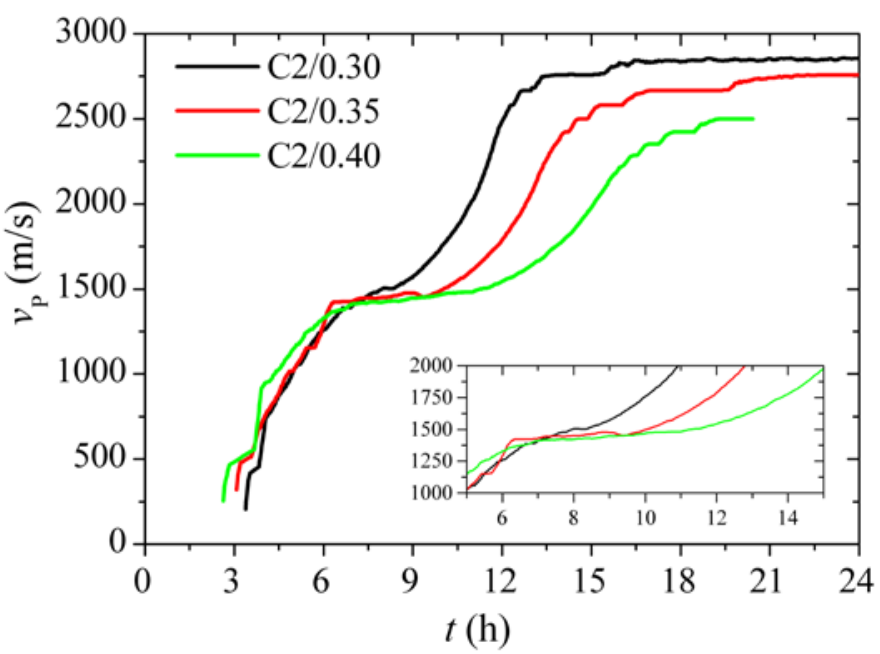

Figure 8 Influence of w/c ratio and cement fineness on the development of the $v_{\mathrm{P}}-t$ curves during the first 24 hours, a) C1, 1.3\% PCE2, b) C2, 1.3\% PCE2.

To analyze the results presented in Figs. 7 and 8 in more detail, the $d_{\mathrm{p}}$ values with respect to admixture dosage, w/c ratio, and cement fineness are summarized in Fig. 9. The presented $d_{\mathrm{p}}$ values were obtained from Figs. 7 and 8 on the basis of the procedure, described in Fig. 6. Even though the $d_{\mathrm{p}}$ values increase with the increasing dosage of PCE, this increase is not unique and is influenced by the w/c ratio and cement fineness significantly. The increase is more evident in the case of higher $\mathrm{w} / \mathrm{c}$ ratio (compare mixtures $\mathrm{C} 2, \mathrm{w} / \mathrm{c}=0.30$ and $\mathrm{C} 2, \mathrm{w} / \mathrm{c}=0.40$, Fig. 9a) and lower cement fineness (compare mixtures $\mathrm{C} 1, \mathrm{w} / \mathrm{c}=0.30$ and $\mathrm{C} 2$, w/c $=$ 0.30, Fig. 9a). Also, increase in the $d_{\mathrm{p}}$ values with increasing w/c ratio is clearly evident from Fig. 9b and is again more pronounced when cement type C1 with lower fineness was used (refer to Table 1).

a)

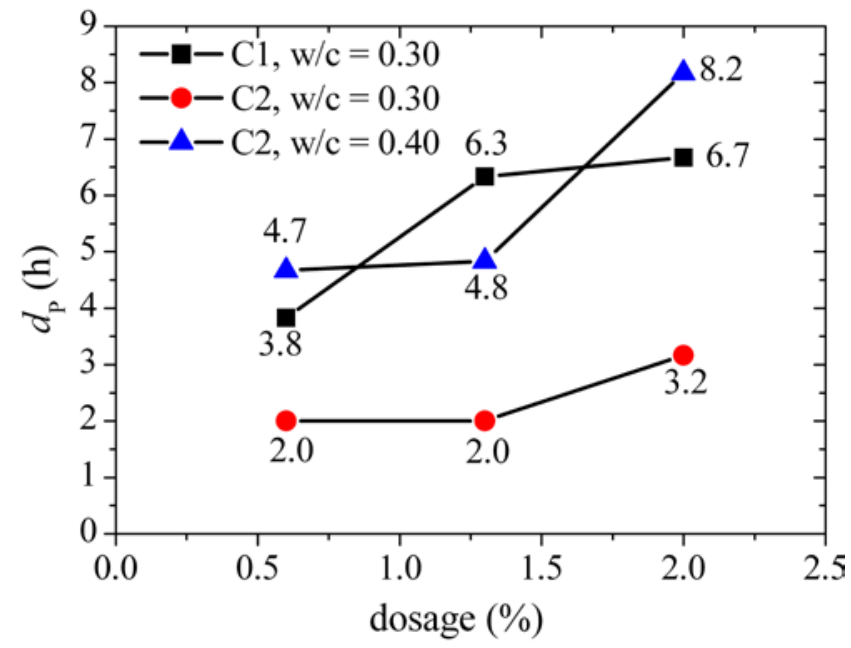

b)

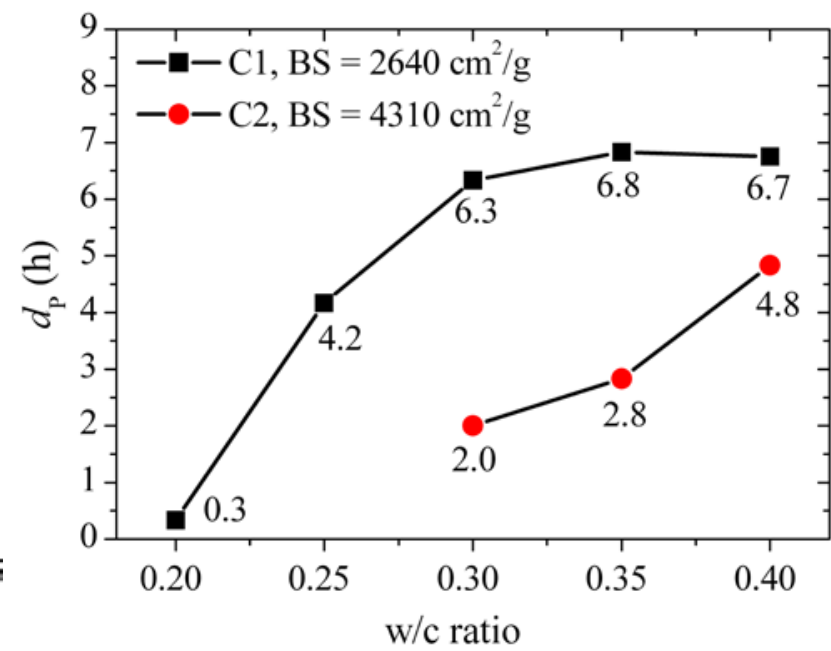

Figure 9 The values of $d_{\mathrm{p}}$ influenced by, a) PCE dosage, b) cement paste composition (1.3\% PCE2).

\subsection{Validation of the US measurements}

In section 4.1.1 it was indicated that the time $t_{v \mathrm{PI} 2}$ when the second inflection point $v_{\mathrm{PI} 2}$ appears on the $\mathrm{d} v_{\mathrm{P}}$ - $t$ curve corresponds to the time $t_{T 11}$ of the first inflection point $T_{\mathrm{I} 1}$ on the $\mathrm{d} T$ - $t$ curves in the case of reference cement paste mixture (refer to Fig. 2). Due to the well known effect of the SPs to delay the point at which the exothermic rate show rapid increase and the time of the highest temperature rise [9, 10], this phenomenon was used as a validation of the presented US results. The development of the $v_{\mathrm{P}}$ in time was therefore compared to the temperature development for all cement paste mixtures used in the 
study. In Fig. 10, the relationship between $t_{\mathrm{vPI} 2}$ and $t_{T 11}$ times is presented for cement pastes from the first (Fig. 10a) and the second (Fig. 10b) part of the experimental work.

a)

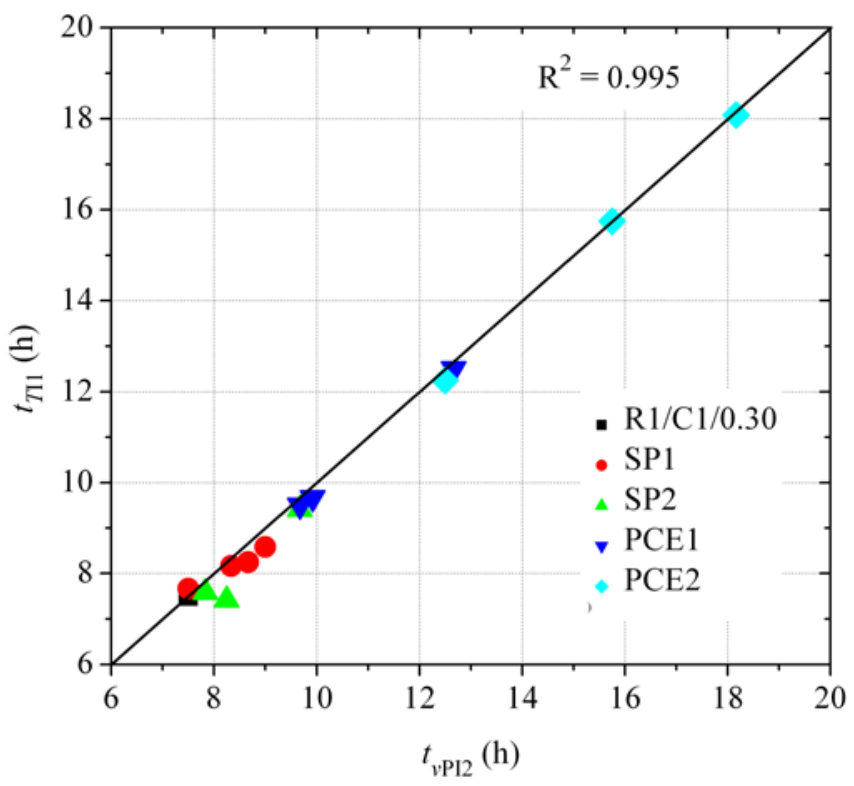

b)

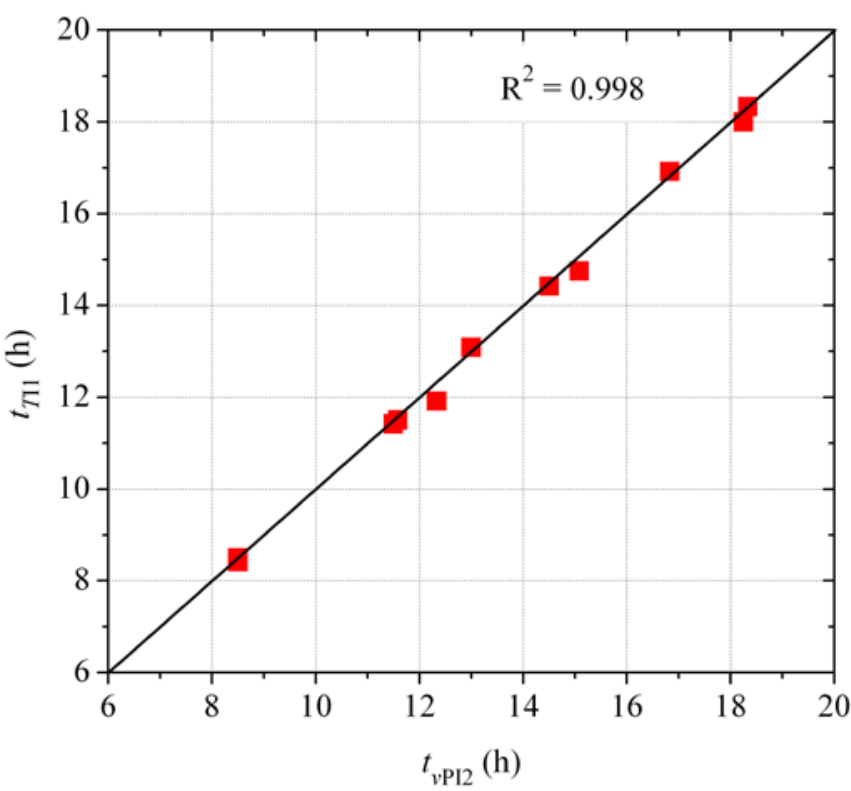

Figure 10 Relationship between $t_{\mathrm{vPI} 2}$ and $t_{\mathrm{TI} 1}$ characteristic points for all cement paste mixtures used in the study, a) mixtures from the first part, b) mixtures from the second part.

A strong linear correlations and high correlation coefficients indicate that $t_{\mathrm{vPI} 2}$, representing the time when the $v_{\mathrm{P}}$ increases at its maximum rate corresponds very well to the time $t_{T 11}$, representing the time of the maximum rate of temperature rise. The addition of different types and dosages of superplasticizers does not influence this phenomenon, indicating that both US and temperature measurements detect exactly the same delay of the time when the hydration process reaches its maximum rate, caused by the presence of SPs. Taking into account that the determinations of $v_{\mathrm{P}}$ and $T$ are completely independent of each other, these results clearly validate the ability and accuracy of the USWT method to detect the influence of SPs on the hydration process and formation of structure of the materials.

\section{Discussion}

The experimental results have shown that the presence of SP influences the development of the $v_{\mathrm{P}}-t$ curves significantly, resulting in lower $v_{\mathrm{P}}$, especially at very early ages. Since the amount of the connected solid phase was found to be the most important parameter which influences early development of the $v_{\mathrm{P}}$ through cementitious materials $[28,29]$, the results of this study prove that the incorporation of the SP clearly affects both the morphology and the grow rates of the hydrates formed $[8,14]$ and thus retard the formation of the solid network frame. This can be explained by the fact that the SP admixtures have the ability to overcome Van der Waals attractive inter-particle (or inter-cluster [29]) forces by imparting a stronger repulsive force at the surface-liquid interface.

Even though this phenomenon is valid for all SPs in this study, significant differences were observed when different types and dosages of SP were incorporated. In the case of the sulfonate naphthaleneformaldehyde SPs (SP1, SP2), the $v_{\mathrm{P}}-t$ curves evolved more smoothly indicating a relatively steady development of the hydration products and the connected solid phase in the microstructure of the material. On the contrary, a completely different shape of the $v_{\mathrm{p}}-t$ curves was observed when the polycarboxylate ether SPs (PCE1, PCE2) were used. In this case, a clearly recognizable plateau occurs on the $v_{\mathrm{P}}-t$ curves at the time when the $v_{\mathrm{P}}$ reaches the $v_{\mathrm{P}}$ in water $\left(v_{\mathrm{P}} \approx 1450 \mathrm{~m} / \mathrm{s}\right)$. This value of $v_{\mathrm{P}}$ was found to be a good estimator of the beginning of the intensive setting period of cement pastes [16] while the earlier increase in $v_{\mathrm{P}}$ is believed to be associated with some other phenomena that have no influence on the setting process [33]. Consequently, the presence of the plateau can be unambiguously related to the 
intensive retardation of the formation of the connected solid network frame caused by the ability of the PCEs to prevent cement agglomeration by inducing electrostatic repulsion and steric hindrance and thus to prevent the close contact of the hydrating particles.

Generally, the length of the plateau increases with the increasing dosage of the SP, increasing w/c ratio, and decreasing cement fineness. The plateau length is therefore inversely proportional to the specific surface area of the solid phases (hydrating cement particles) dictated by w/c ratio and cement fineness, which further substantiates the assumption that the specific surface area of the solid phase significantly affects the performance of the SP [1]. This could be related to the fact that with the increasing specific surface area of the hydrates, a higher amount of the SP can be incorporated directly on the surface of the hydration products. Thus, a lower amount of the SP remains free in a mixing water and a thinner layer of the adsorbed compounds is formed on the surface of the hydrates, resulting in a weaker and shorterlasting repulsive forces at the surface-liquid interface and consequently shorter plateau length $d_{\mathrm{p}}$.

Even though the plateau length increases with the increasing dosage of PCE, this relationship is not linear. Moreover, the relationship is not unique and depends highly on the cement fineness and w/c ratio. Due to the adsorption phenomena described in the previous paragraph, the differences in $d_{\mathrm{p}}$ values are more evident in the case of lower specific surface area of the solids, originating from higher w/c ratio and lower cement fineness and consequently stronger and longer-lasting steric repulsive forces that prevent re-agglomeration of the hydrating cement particles and liberate the water trapped within the flocculated structure.

When compared to the reference cement paste, the times at which the inflection points occur are delayed significantly in the case when all types of SP were used. Since the first inflection point $v_{\mathrm{PI} 1}$ on the $v_{\mathrm{P}}-t$ curve was found to be a good estimator of the initial setting time of cement pastes [16, 33], the delay in the setting time of all superplasticized mixtures is proven which increases with the increasing dosages of each SP. This is a well known phenomenon which has been already indicated by many authors when various experimental techniques have been utilized [4, 11, 13, 14]. However, the results of this study show that the polycarboxylate ether SPs are more effective in delaying these milestones in the microstructure formation process than the sulfonate naphthalene-formaldehyde types of SPs.

Similar $v_{\mathrm{P}}$ values at the inflection points for all cement pastes indicate that the type and dosage of the SP admixtures do not affect the absolute amount of the total and connected solid phase, developed during the hydration process. Approximately the same long-term values of the $v_{\mathrm{P}}$ were also observed for all cement paste mixtures with the same w/c ratio and cement fineness. Since the $v_{\mathrm{P}}$ was found to follow the evolution of the total solid fraction when the plateau at stage 5 is reached $[28,29]$, approximately the same final volume of the total solid phase is expected for these mixtures. On the basis of the unique linear relationship between the $v_{\mathrm{P}}$ and compressive strength of cementitious materials [29], the incorporation of different types and dosages of superplasticizers, while maintaining the w/c ratio, does not seem to affect the mechanical properties of the cement based materials at later ages. This is also in good agreement with the assumption presented by other researchers [8, 14, 37].

\section{Conclusions}

In this paper, the sensitivity of the ultrasonic wave transmission method to detect the influence of superplasticizers on the solidification process of cement pastes was studied. Several important conclusions can be obtained from this study which further substantiate the results presented by other researchers when some other advanced techniques have been utilized:

1) On the basis of the US velocity curves and their derivatives, five stages are clearly identified during the microstructure formation process of cement pastes which are substantiated by temperature measurements. The presence of different SP types and dosages do not affect this division. Using ANOVA technique, high repeatability of the $v_{\mathrm{P}}-t$ curves was established.

2) $v_{P}-t$ curves are strongly affected by the presence of different types and dosages of SPs in the cement paste composition, resulting in lower $v_{\mathrm{P}}$ values especially at very early ages. This proves that the incorporation of the SP in cement pastes retards the formation of structure process of the material. With increasing dosages of SP, the $v_{\mathrm{P}}$ decreases and vice versa. 
3) Significant differences in the evolution of the $v_{\mathrm{P}}-t$ curves were observed when the sulfonate naphthalene-formaldehyde and the polycarboxylate ether superplasticizers were used, indicating different working principles of these SPs. In the case when PCEs were used, the plateau occurs when the $v_{\mathrm{P}}$ reaches the velocity in water, indicating an intensive retardation of the development of the connected solid phase during this setting period. On the contrary, uniform and steady development of the microstructure was observed in the case when the sulfonate naphthaleneformaldehyde types of the SPs were used.

4) The length of the plateau on the $v_{\mathrm{P}}-t$ curve increases with the increasing dosage of PCE and is inversely proportional to the specific surface area of the hydration products developed. This proves the assumptions that the specific surface area of the solid phase affects the performance and adsorption phenomena of the PCE importantly.

5) The incorporation of the SP admixtures do not affect the absolute amount of the total and the connected solid phase, developed during the hydration process. Approximately the same longterm $v_{\mathrm{P}}$ values are observed for all cement paste mixtures with the same w/c ratio and cement fineness, proving that SP admixtures have no important influence on the compressive strength of the materials at later ages while maintaining the w/c ratio.

6) The time when the rate of the $v_{P}$ evolution reaches its maximum corresponds to the time when the material temperature reaches its maximum rate. This phenomenon is not influenced by the presence of different types and dosages of SPs and therefore proves the efficiency and accuracy of the USWT method to detect the delay in the formation of structure and setting process of cement paste, caused by the presence of these admixtures.

The results of this study demonstrate the ability of the presented USWT method to detect several well known effects of the SPs on the setting and hardening properties of cement based materials if properly considered. Moreover, using this method, some other interesting phenomena can be identified which may contribute to a better understanding of working principles of these admixtures. The method is practical, low cost and easily manageable and is therefore applicable in laboratory conditions as a research method as well as directly in situ. Consequently, these results expand the range of application of the USWT method to a high degree.

\section{Acknowledgement}

The authors gratefully acknowledge the financial support from Slovenian Research Agency as a part of the research project No. Z2-4069.

\section{References}

[1] K. Yamada, Basics of analytical methods used for the investigation of interaction mechanism between cements and superplasticizers, Cem. Concr. Res. 41 (7) (2011) 793-798.

[2] D. Bonen, S. L. Sakar, The superplasticizer adsorption capacity of cement paste, pore solution composition, and parameters affecting flow loss, Cem. Concr. Res. 25 (7) (1995) 1423-1434.

[3] R. J. Flatt, Y. F. Houst, A simplified view on chemical effects perturbing the action of superplasticizers, Cem. Concr. Res. 31 (8) (2001) 1169-1176.

[4] L. Z. Xiao, Z. J. Li, X. S. Wei, Selection of superplasticizer in concrete mix design by measuring the early electrical resistivities of pastes, Cem. Concr. Compos. 29 (5) (2007) 350-356.

[5] J. Cheung, A. Jeknavorian, L. Roberts, D. Silva, Impact of admixtures on the hydration kinetics of Portland cement, Cem. Concr. Res. 41 (12) (2011) 1289-1309.

[6] J. M. Torrents, J. Roncero, R. Gettu, Utilization of impedance spectroscopy for studying the retarding effect of superplasticizer on setting of cement, Cem. Concr. Res. 28 (9) (1998) 13251333. 
[7] T. Emoto, T. A. Bier, Rheological behavior as influenced by plasticizers and hydration kinetics, Cem. Concr. Res. 37 (5) (2007) 647-654.

[8] J. Roncero, Effect of superplasticizers on the behavior of concrete in the fresh and hardened states: implications for high performance concretes, PhD Thesis, Barcelona, 2000.

[9] Y. Zhang, W. Sun, S. Liu, Study on the hydration heat of binder paste in high-performance concrete, Cem. Concr. Res. 32 (9) (2002) 1483-1488.

[10] B. Lothenbach, F. Winnefeld, R. Figi, The influence of superplasticizers on the hydration of Portand cement, Eawag-Empa Library (2007) 1-12, Montreal, Canada.

[11] M. Heikal, M. S. Morsy, I. Aiad, Effect of polycarboxylate superplasticizer on hydration characteristics of cement pastes containing silica fume, Ceramic - Silikaty 50 (1) (2006) 5-14.

[12] A. Zingg, F. Winnefeld, L. Holzer, J. Pakusch, S. Becker, R. Figi, L. Gauckler, Interaction of polycarboxylate-based superplasticizers with cements containing different $\mathrm{C}_{3} \mathrm{~A}$ amounts, Cem. Concr. Compos. 31 (3) (2009) 153-162.

[13] W. Schmidt, H. J. H. Brouwers, H. C. Kuehne, B. Meng, Correlation between setting, heat evolution, and deformations of cementitious binder systems depending on type and amount of superplasticizer, In: A. Palomo, A. Zaragoza, J. C. López (eds.): Proceedings of the 13th International Congress on the Chemistry of Cement, Madrid, Spain, July 2011.

[14] J. Roncero, S. Valls, R. Gettu, Study of the influence of superplasticizers on the hydration of cement paste using nuclear magnetic resonance and X-ray diffraction techniques, Cem. Concr. Res. 32 (1) (2002) 103-108.

[15] L. Ferrari, J. Kaufmann, F. Winnefeld, J. Plank, Multi-method approach to study influence of superplasticizers on cement suspensions, Cem. Concr. Res. 41 (10) (2011) 1058-1066.

[16] G. Trtnik, G. Turk, F. Kavcic, V. Bokan Bosiljkov, Possibilities of using the ultrasonic wave transmission method to estimate initial setting time of cement paste, Cem. Concr. Res. 38 (11) (2008) 1336-1342.

[17] G. Trtnik, M. I. Valic, F. Kavcic, G. Turk, Comparison between two ultrasonic methods in their ability to monitor the setting process of cement pastes, Cem. Concr. Res. 39 (10) (2009) 876-882.

[18] G. Ye, Experimental study and numerical simulation of the development of microstructure and permeability of cementitious materials, PhD Thesis, Delft, 2003.

[19] H. W. Reinhardt, C. U. Grosse, Continuous monitoring of setting and hardening of mortar and concrete, Constr. Build. Mater. 18 (3) (2004) 145-154.

[20] T. Chotard, N. Gimet-Brert, A. Smith, D. Fargeto. J. P. Bonnet, C. Gault, Application of ultrasonic testing to describe the hydration of calcium aluminate cement at the early age, Cem. Concr. Res. 31 (3) (2001) 405-412.

[21] T. Kamada, S. Uchida, K. Rokugo, Non-destructive evaluation of setting and hardening of cement paste based on ultrasonic propagation characteristics, J. Adv. Concr. Techn. 3 (3) (2005) 343-353.

[22] J. Zhu, S. H. Kee, D. Han, Y. T. Tsai, Effect of air voids on ultrasonic wave propagation in early age cement pastes, Cem. Concr. Res. 41 (8) (2011) 872-881.

[23] Y. Zhang, W. Zhang, W. She, L. Ma, W. Zhu, Ultrasound monitoring of setting and hardening process of ultra-high performance cementitious materials. NDT\&E Int . 47 (4) (2012) 177-184.

[24] N. Robeyst, C. U. Grosse, N. De Belie, Measuring the change in ultrasonic p-wave energy transmitted in fresh mortar with additives to monitor the setting, Cem. Concr. Res. 39 (10) (2009) 868-875.

[25] N. Robeyst, E. Gruyaert, C. U. Grosse, N. De Belie, Monitoring the setting of concrete containing blast-furnace slag by measuring the ultrasonic p-wave velocity, Cem. Concr. Res. 38 (10) (2008) 1169-1176. 
[26] N. De Belie, C. U. Grosse, J. Kurz, H. W. Reinhardt, Ultrasound monitoring of the influence of different accelerating admixtures and cement types for shotcrete on setting and hardening behavior, Cem. Concr. Res. 35 (11) (2005) 2087-2094.

[27] H. K. Lee, K. M. Lee, Y. H. Kim, H. Yim, D. B. Bae, Ultrasonic in-situ monitoring of setting process of high-performance concrete, Cem. Concr. Res. 34 (4) (2004) 631-640.

[28] G. Ye, P. Lura, K. van Breugel A. L. A. Fraaij, Study on the development of the microstructure in cement-based materials by means of numerical simulation and ultrasonic pulse velocity measurement, Cem. Concr. Compos. 26 (5) (2004) 491-497.

[29] G. Ye, K. van Breugel, A. L. A. Fraaij, Experimental study on ultrasonic pulse velocity evaluation of the microstructure of cementitious materials at early age, HERON 46 (3) (2001) 161-167.

[30] EN 196-1:2005, Methods of testing cement - Part 1: Determination of strength, April 2005.

[31] C. M. Sayers, A. Dahlin, Propagation of ultrasound through hydrating cement paste at early times, Adv. Cem. Based Mater. 1 (1) (1993) 12-21.

[32] J. R. Rapoport, J. S. Popovics, V. K. Subramaniam, S. P. Shah, Using ultrasound to monitor stiffening process of concrete with admixtures, ACI Mater. J. 97 (2000) 675-683.

[33] T. Voigt, C. U. Grosse, Z. Sun, S. P. Shah, H. W. Reinhardt, Comparison of ultrasonic wave transmission and reflection measurements with P- and S-waves on early age mortar and concrete, Mater. Struct. 38 (8) (2005) 729-738.

[34] J. Keating, D. J. Hannant, A. P. Hibbert, Comparison of shear modulus and pulse velocity techniques to measure the build-up of structure in fresh cement pastes used in oil well cementing, Cem. Concr. Res. 19 (4) (1989) 554-566.

[35] C. M Sayers, R. L. Grenfell, Ultrasonic propagation through hydrating cements, Ultrasonics 31 (3) (1993) 147-153.

[36] W. Hays, Statistics, Fifth edition, Harcour Brace College Publishers, University of Texas at Austin, 1991.

[37] A. A. Ramezanianpour, V. Sivasundaram, V. M. Malhotra, Superplasticizers: their effect on the strength properties of concrete made with ASTM type I and V cements, Concr. Int. 17 (4) (1995) 30-35. 